\title{
O VERDE HISTÓRICO DA PRAÇA EUCLIDES DA CUNHA
}

\author{
Joelmir Marques da Silva ${ }^{12}$
}

\section{RESUMO}

Os primeiros jardins públicos, de caráter moderno, foram criados no Brasil por Roberto Burle Marx na década de 1930 na cidade do Recife. Para o paisagista o desenho de um jardim é uma reintegração estética dos elementos da paisagem envolvente onde a vegetação é o elemento principal. Com essa intenção Burle Marx projetou um conjunto de treze jardins públicos, entre 1935 a 1937 e, dentre eles, destaca-se Praça Euclides da Cunha por ser um dos seus primeiros projetos. Tendo sido restaurada em 2004, na perspectiva de seu reconhecimento como jardim histórico, ações de conservação vem sendo praticadas, o que exige o conhecimento do verde histórico o que se configura como um estudo da arqueologia botânica. O problema que caracteriza o presente artigo estabeleceu-se em torno da ausência de um entendimento do verde histórico da Praça Euclides da Cunha. Para tanto, objetivou-se identificar a composição florística do projeto original e a atual dessa praça bem como compará-las com vistas a garantir ações de conservação que concorrerá para a autenticidade. Observou-se que apesar das intervenções ocorridas com relação à vegetação indicada no projeto original, a ideia do paisagista permanece.

Palavras-chaves: Jardim histórico; Patrimônio Cultural; Conservação; Recife.

\section{THE GREEN HISTORIC OF THE EUCLIDES DA CUNHA SQUARE}

\section{ABSTRACT}

In the 1930s, the modern garden was created in Recife by Roberto Burle Marx. For him the garden design is a reintegration of the aesthetic components of the landscape in which vegetation is the main element. With this intention Burle Marx designed a set of thirteen public gardens between 1935 to 1937, and among them stands out Square Euclides da Cunha for being one of the first projects. Having been restored in 2004 with a view to its recognition as a historic garden, conservation action has been committed, which requires knowledge of historic vegetation which is configured as an archaeology botanic study. The problem of this study established around of the lack of an understanding of historic vegetation of Euclides da Cunha Square. This study aims to identify the original and current floristic composition of this square and compare them to ensure conservation actions in order to achieve garden authenticity. It was observed that despite of the interventions related with the vegetation of the original projects, the idea of the landscape designer has remained.

Keywords: Historic garden; Cultural heritage; Conservation; Recife.

\footnotetext{
${ }^{1}$ Biólogo, Mestre e Doutorando em Desenvolvimento Urbano pela Universidade Federal de Pernambuco. Pesquisador do Laboratório da Paisagem do Departamento de Arquitetura e Urbanismo da Universidade Federal de Pernambuco.Joelmir_marques@hotmail.com ${ }^{2}$ recebido em 24.04.2013 e aceito para publicação em 15.03.2014
} 
O ano de 1935 marca um momento na história do paisagismo na cidade do Recife, capital do Estado de Pernambuco, Nordeste do Brasil, com a chegada do paisagista Roberto Burle Marx, que assumiu a direção do Setor de Parques e Jardins do Departamento de Arquitetura e Construção a convite do então governador Carlos de Lima Cavalcanti.

A presença de Burle Marx no Recife foi motivo de várias matérias nos principais jornais da época, nos quais por muitas vezes ele foi considerado como a esperança de uma mudança na fisionomia do Recife, uma vez que o paisagista projetava "jardim e praças que a cidade precisa para compor a sua propria paysagem e dar conforto, hygiene e belleza à sua população, mas sem quebrar as linhas e sem fugir ao sentido da natureza ambiente” (Diario da Tarde, 14/03/1935a, p. 2).

A expectativa era de se ter, com as construções e/ou remodelações dos jardins, uma orientação racional, regional e moderna, uma vez que, na visão de Burle Marx “O jardim é em sua essência natureza organizada, subordinada a leis architectonicas" (Diario da Manhã, 22/05/1935, p. 1) e se faz necessário que "os homens consigam compreender a paisagem elaborada através de uma ordenação consciente da natureza. Mas é preciso compreender a natureza selvagem, não elaborada, para tirar dela grande lição” (Marx in Cals, 1995, p.74).

Iniciando suas atividades no Setor de Parques e Jardins, Burle Marx cria um plano de aformoseamento e projeta os primeiros jardins públicos de sua carreira, como é o caso da Praça Euclides da Cunha, projetada em 1935. Com essa ação, o paisagista dá às praças, largos e parques do
Recife um caráter autóctone, integrando-os a paisagem urbana pelo uso de plantas que se encontravam nos arredores, e que por muitas vezes caracterizavam um lugar, como se pode ver na seguinte fala do paisagista ao justificar o uso da Acrocomia intumescens em seus projetos “ $a$ Macaíba ou Macaúba que, com seu fuste ventricoso, tão bem caracteriza a paisagem dos arredores de Olinda e Recife" (Marx, 1985, p. 71 in Seminário de Tropicologia: homem, terra e trópico, 1992). Para Burle Marx essa era a forma de semear nos jardins a alma brasileira.

Higiene, educação e arte, foram os princípios norteadores que Burle Marx adotou ao projetar os jardins no Recife, onde o elemento vegetal tornouse protagonista. Desta forma, por se constituírem documentos únicos, com personalidades próprias e carregados de significados, seis jardins públicos, os mais representativos, de um total de dezesseis, projetados por Burle Marx, entre 1935 a 1958, foram inventariados pelo Laboratório da Paisagem da Universidade Federal de Pernambuco com o intuito de solicitar o tombamento, como Patrimônio Cultural Nacional, ao Instituto do Patrimônio Histórico e Artístico Nacional (IPHAN), fato que se concretizou em 2008, e entre eles está a Praça Euclides da Cunha.

Por tanto, objetivou-se com este artigo identificar a composição florística do projeto original e a atual da Praça Euclides da Cunha, bem como comparálas, com vistas a garantir ações de conservação que concorrerá para a autenticidade da vegetação, uma vez que a praça é considerada um Jardim Histórico, ou seja, um monumento vivo.

Joelmir Marques da Silva 


\section{O objeto}

A Praça Euclides da Cunha (Figura 1) está localizada no bairro da Madalena, Recife, Pernambuco, Brasil, e configura-se como um dos primeiros jardins públicos da Carreira do paisagista Roberto Burle Marx e data de 1935. A área onde foi implementada a praça fazia parte do Engenho da
Madalena que, na época, era uma depressão alagada e que anos depois foi aterrada. Antes de receber o nome - Praça Euclides da Cunha -, por Bule Marx, era denominada de Jardim do Benfica. Mais tarde ficou conhecida como Cactário da Madalena e Jardim das Cactáceas.

Figura 1. Praça Euclides da Cunha, 2013.

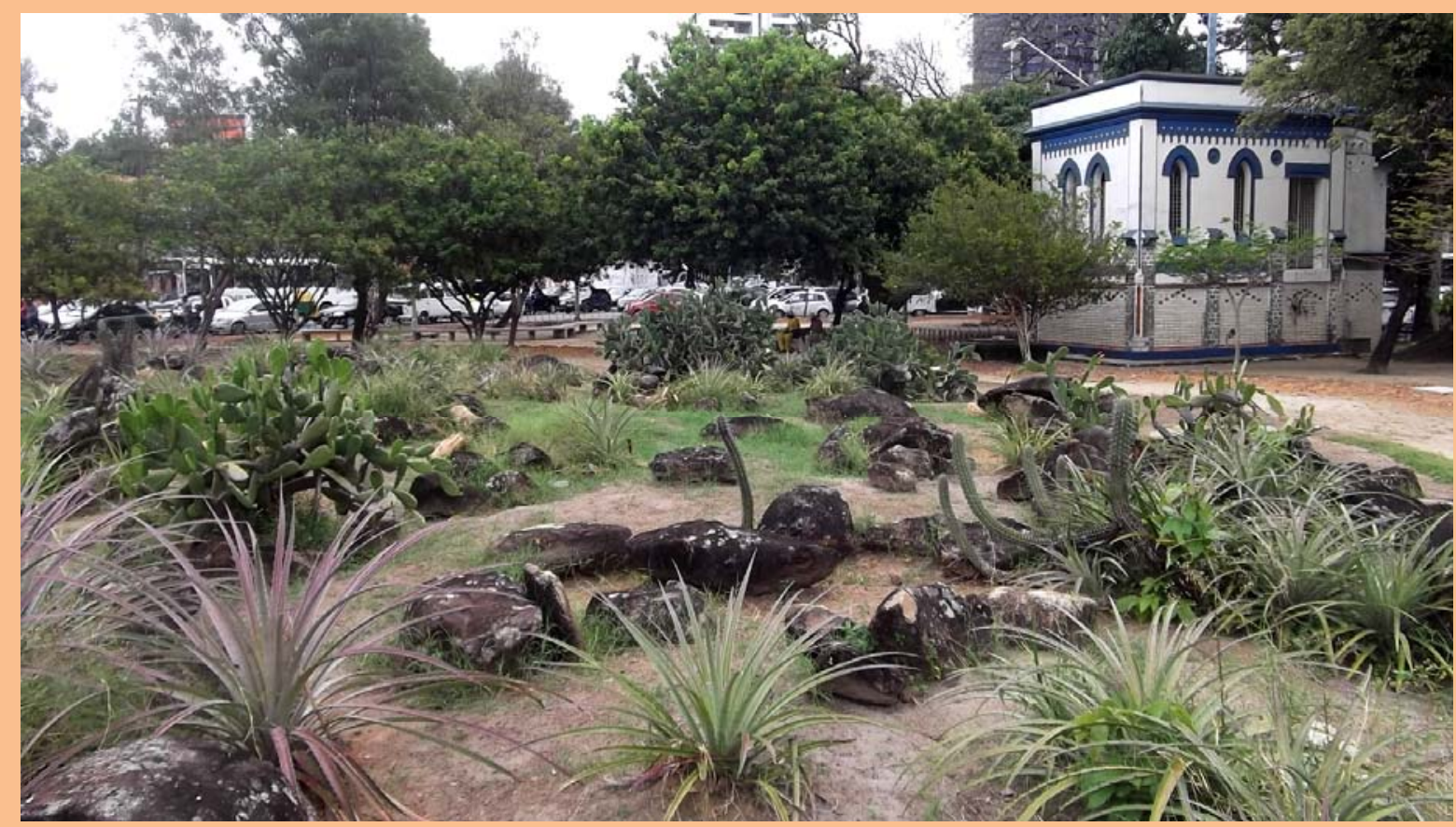

\section{Procedimentos metodológicos}

Pesquisa histórica

Conforme Best (1972, p. 12-13), a "pesquisa histórica descreve o que era". O processo enfoca quatro aspectos: i) investigação; ii) registro; iii) análise e iv) interpretação de fatos ocorridos no passado. Já a pesquisa descritiva delineia o que é.
Aborda também quatro aspectos: i) descrição; ii) registro; iii) análise e iv) interpretação de fenômenos atuais, objetivando o seu funcionamento no presente. A pesquisa bibliográfica, por sua vez, refere-se a fontes secundárias, abrangendo toda a 
bibliografia já tornada pública em relação ao tema de estudo, no entanto, de acordo com Trujillo (1974) não se configura como sendo uma mera repetição do que já foi dito ou escrito sobre o assunto.

Quanto à pesquisa histórica, a técnica utilizada foi a documentação indireta, em que a coleta de dados está restrita a documentos escritos ou não, constituindo o que se denomina de fontes primárias, que englobam: i) jornais de circulação diária; ii) periódicos e iii) iconografias.

A pesquisa em jornais abrangeu o recorte temporal de 1934 a 1937. A escolha desses anos justifica-se pelo fato de ter sido nessa época que ocorreu a

\section{Pesquisa descritiva}

Para a pesquisa descritiva fez-se uso da documentação direta como técnica, que constitui-se no levantamento de dados no próprio local (área de estudo). Esses dados podem ser obtidos de duas maneiras: i) no campo ou ii) no laboratório. Para atingir o objetivo da pesquisa foi realizado o estudo de campo, que conforme Tripodi et al., (1975, p. 42-71) “divide-se em três grandes grupos: i) quantitativo-descritivo; ii) exploratório e iii) experimental”. Mais uma vez, reportando ao objetivo apenas os dois primeiros grupos foram abordados.

$\mathrm{O}$ estudo quantitativo-descritivo referiu-se ao levantamento florístico da praça. Para tanto foi utilizado o método de censo, ou seja, foram inventariados todos os indivíduos existentes na área. A identificação taxonômica dos espécimes foi realizada in loco apenas para o caso de espécies muito bem conhecidas; para as demais, foram maior produção paisagística de Burle Marx no Recife. Para tanto, foram consultados os jornais 'Diario da Manhã', 'Diario da Tarde’, 'Jornal do Commercio' e 'Diario de Pernambuco'. Com a consulta aos jornais teve-se acesso aos discursos de Burle Marx que expressam suas intenções sobre a praça, objeto de estudo.

No que se refere ao material iconográfico, foram consultados os registros fotográficos das décadas de 1940 e 1950; os Desenhos de Burle Marx para a Praça Euclides da Cunha e registro fotográfico que constam nos jornais Diario da Manhã e Diario da Tarde.

coletadas amostras de material botânico fértil e herborizados para posterior identificação por especialistas e comparações com exsicatas do Herbário UFP - Geraldo Mariz da Universidade Federal de Pernambuco; do Neotropical Herbarium Specimens; do Neotropical Live Plant Photos e do TROPICOS $®$. Para caracterizar a vegetação foi elaborada uma lista florística segundo o sistema de classificação de Cronquist (1981) relacionando as famílias e as espécies. A confirmação dos nomes foi obtida consultando o índice de espécies pelo site do Missouri Botanical Garden, o que resultou no inventário atual da referida praça.

Para a análise de campo de caráter exploratório, fez-se uso dos estudos exploratório-descritivos combinados que tem por objetivo descrever, na medida do possível, determinado fenômeno, como por exemplo, o estudo de um caso para o qual serão realizadas análises empíricas e teóricas. 
Pesquisa bibliográfica

Para a pesquisa bibliográfica, e dentro das categorias que englobam, foi selecionada a 'publicação' que abarcou livros, teses, dissertações,

monografias, periódicos, publicações avulsas e pesquisas.

\section{RESULTADOS E DISCUSSÃO}

\section{A Praça Euclides da Cunha e sua história}

Nas palavras de Burle Marx: “ $a$ obra Os Sertões de Euclides da Cunha influiu fortemente em minha decisão de construir o cactário da Madalena” (MARX, 1987, p. 73). Com o projeto da Praça Euclides da Cunha, o paisagista buscou semear a alma brasileira, no entanto, evocar a brasilidade naquele momento significava uma oposição estrutural entre o campo e a cidade.

Euclides da Cunha em sua obra literária, Os Sertões, ao tratar da brasilidade, se refere à pureza atrelada ao sertão, uma vez que as cidades do litoral configuravam-se como sombrias e promiscuas o que inviabilizava a construção da almejada brasilidade. Segundo Euclides da Cunha "O sertão é o lugar do esquecimento" (CUNHA, 1909, p. 111). Foi esse esquecimento que o País impôs ao sertão que propiciou condições da “criação” de um povo original que passou a expressar a alma nacional.

No projeto paisagístico da Praça Euclides da Cunha, Burle Marx emprega uma particularidade climática e botânica até então totalmente ignorada a vegetação da caatinga. Nas palavras de Joaquim Cardozo "no jardim do Largo do Benfica, além das árvores sempre bem escolhidas, fez plantações de cáctus e arbustos das caatingas pernambucanas (...) fornecendo ao morador do Recife uma visão do sertão seco do seu estado” (2009, p. 171).
As plantas da caatinga assumiam, na época, uma posição ambígua - de ser nativa e exótica ao mesmo tempo. Nativa, por fazer parte de uma das mais belas formações florestais que temos no Brasil; e exótica, por ser tão desconhecida e porque não dizer tão rejeitada pela sociedade (Figura 2 e 3). Diante disto, a Praça Euclides da Cunha configura- se até hoje como o único espaço público brasileiro com tais características.

Além da questão social e geográfica, Os Sertões, em sua subseção intitulada 'As caatingas' nos traz precisas informações sobre a vegetação típica da região abarcando aspectos florísticos, fitossociológicos, morfológicos, ecofisiológicos, da biologia floral e da interação planta-solo configurando-se como um compêndio botânico. Um exemplo disto podemos ver na seguinte passagem:

Os mulungus rotundos, à borda das cacimbas cheias, estadeiam a púrpura das largas flores vermelhas, sem esperar pelas folhas, as caraíbas e baraúnas altas refrondescem à margem dos ribeirões refertos; ramalham, ressoantes, os marizeiros esgalhados, à passagem das virações suaves; assomam, vivazes, amortecendo as truncaduras das quebradas, as quixabeiras de folhas pequeninas e frutos que lembram contas de ônix; mais virentes, adensam-se os icozeiros pelas várzeas, sob o ondular festivo das copas dos ouricuris: ondeiam, 
móveis, avivando a paisagem, acamandose nos plainos, arredondando as encostas, as moitas floridas do alecrim-ostabuleiros, de caules finos e flexíveis; as umburanas perfumam os ares, filtrando-os nas frondes enfolhadas, e - dominando a revivescência geral — não já pela altura senão pelo gracioso do porte, os umbuzeiros alevantam dous metros sobre o chão, irradiantes em círculo, os galhos numerosos (CUNHA, 1909, p. 30).

Figura 2 e 3. Vegetação da caatinga na Praça Euclides da Cunha, 2013.
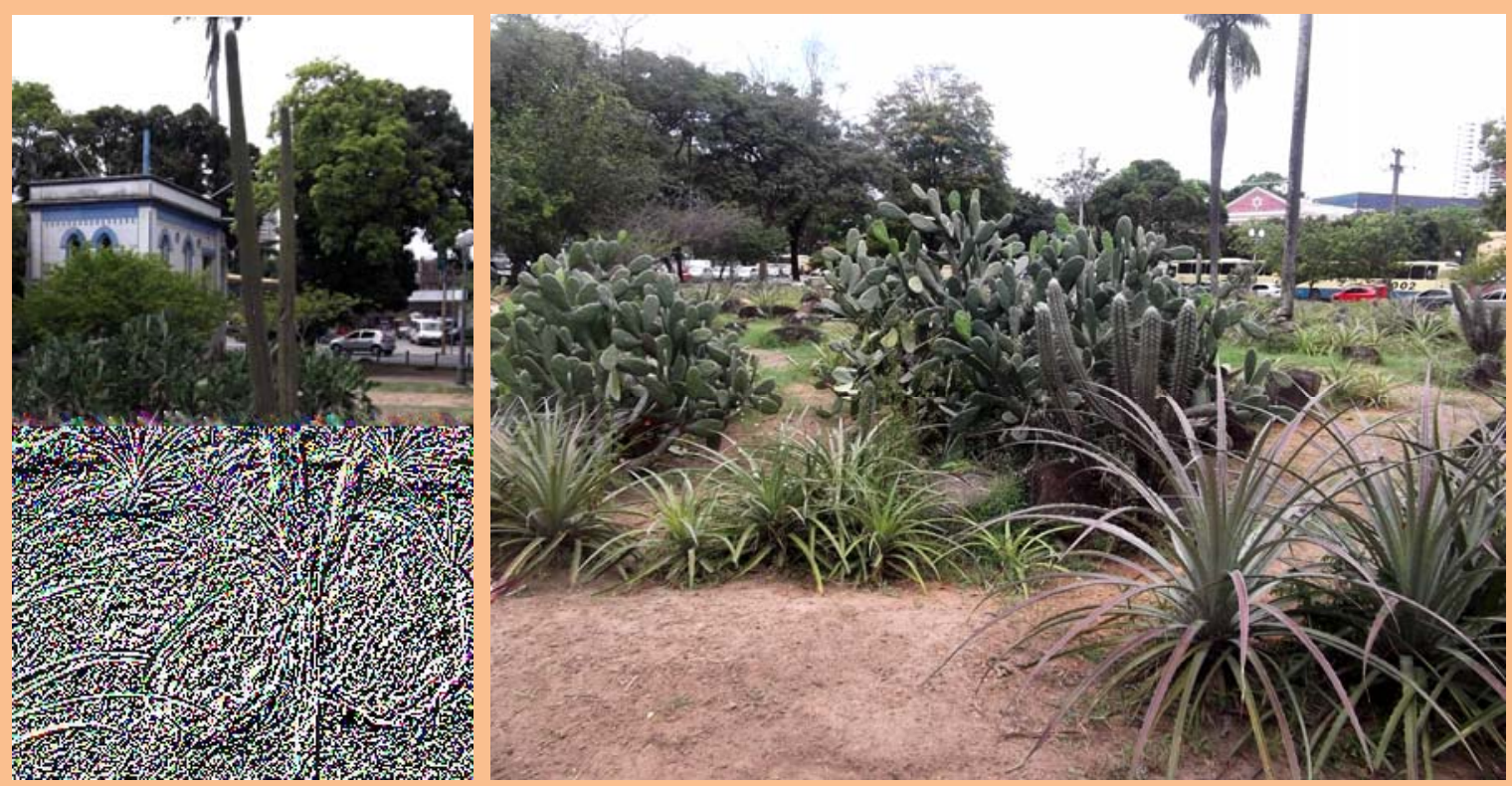

Reunindo o conteúdo do livro Os Sertões com o conhecimento da ecologia, principalmente no que se refere aos grupos ecológicos, adquirido no Jardim Botânico de Dahlem, na Alemanha, diante da classificação do botânico Adolf Engler, Burle Marx cria um jardim, como ele mesmo determinou, de caráter ecológico.

Com a criação da Praça Euclides da Cunha, Burle Marx objetiva “doar a Pernambuco um jardim em que se achem alliadas a hygiene e a arte, ao par da educação e cultura (...)” (DIARIO DA TARDE, 14/03/1935b, p. 1).

No artigo 'Jardins e Parques do Recife: Roberto Burle Marx para o Diario da Tarde' de 14/03/1935b, o paisagista expõe suas intenções para a praça, onde enfatizou a composição florística, justificando o uso de cada espécie.

(...) tencionamos crear um cactario e reunir nelle o maior numero possivel de gêneros brasileiros da familia das cactáceas, como sejam: Cereus, Melocactus, Opuntia, Pilocereus, etc. blocos de pedra e plantas das famílias das Bromeliaceas e Euforbiaceas completarão o ambiente nordestino. Duas alamedas de arvores autochtonas do sertão, tais como: Unbuzeiros, Joazeiros, Páos d'arco, etc., en-volverão a praça pela parte mais externa encontrando-se numa das extremidades onde formarão um pequeno bosque. Terse-á accesso ao passeio interno, por meio de tres pequenas escadas que acompanharão uma rampa grammada. Ao lado dessas escadas vistos alguns exemplares de cactos de grande porte. 
A Figura 4 mostra uma comparação entre uma área da caatinga no Ceará com populações de macambira (Encholirium spectabile) e xiquexique (Pilosocereus gounellei) em dorso de grande lajedo aflorante no entremeio de extensa caatinga com o desenho de perspectiva da Praça Euclides da Cunha feito por Burle Marx em 1935, onde se pode ver, claramente, que o paisagista respeitou as condições ambientais das espécies associadas às questões artísticas do jardim.

Figura 4. (Esquerda) Aspecto da caatinga no Ceará e em (Direita) Desenho feito por Burle Marx para a Praça Euclides da Cunha.
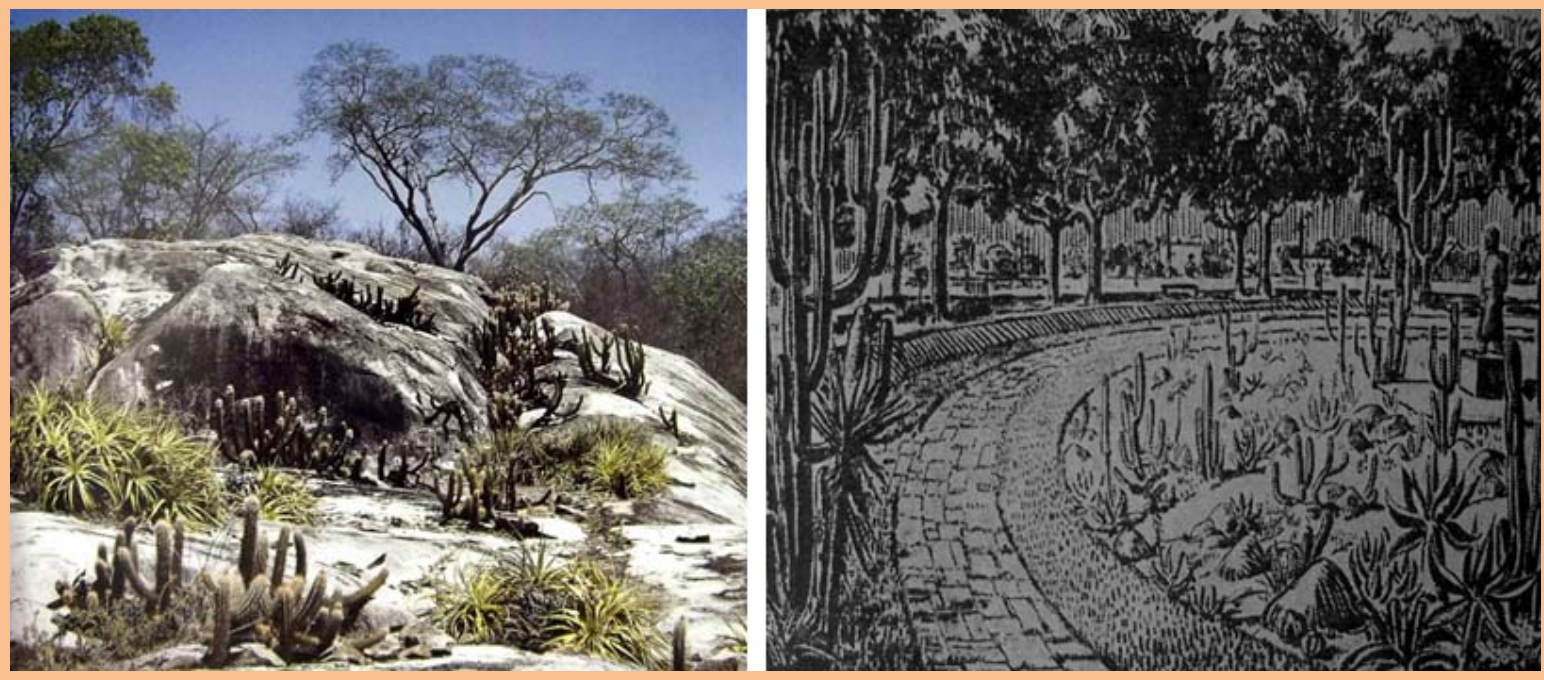

Fonte: AB’SÁBER e MARIGO, 2006 (A) e Diario da Tarde 14/03/1935b (B).

Relacionados às palavras de Burle Marx no Diario da Tarde estavam alguns desenhos feitos pelo paisagista a bico de pena (Figuras 5 e 6). Com os desenhos, podemos perceber além da questão artística, o caráter ecológico do jardim mediante a associação entre os indivíduos de mesma espécie e de espécies diferentes, bem como sua interação com o elemento mineral, as rochas, representando, desta forma, a paisagem da caatinga.
Alguns autores como Euler Sandeville Jr. (2003) e Fabiano Oliveira (2008) reforçam que, além da leitura de 'Os Sertões’ e da experiência vivida no jardim botânico de Dahlem, outro momento importante foi o contato que Burle Marx teve com Mina Klabin Warchavchik que realizou a partir de 1928 jardins adequados às condições brasileiras. 
Figuras 5 e 6. Desenhos feitos por Burle Marx para a Praça Euclides da Cunha.

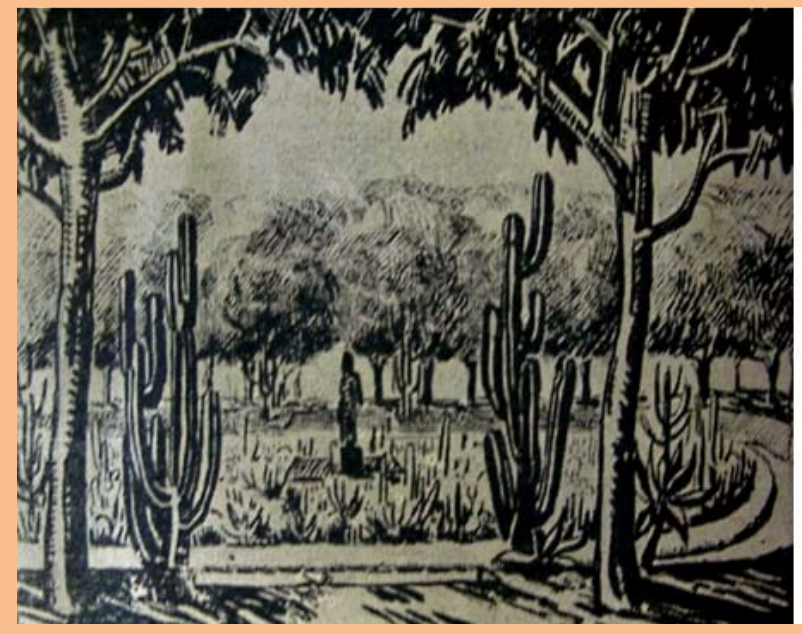

Em sintonia com as discussões modernistas, a paisagista interessou-se na aplicação das plantas tropicais em que o cacto aparece carregado de simbolismo e os jardins foram considerados, recorrentemente, pela historiografia da arquitetura moderna brasileira como uma das principais tentativas de abrasileiramento.

No entanto, os ideais de Burle Marx transcendiam claramente aos de Mina Warchavchik ao somar o caráter cultural de construção de novos valores e percepção perante os elementos da paisagem nordestina. A questão científica de atentar para as questões botânicas e ambientais era algo ausente

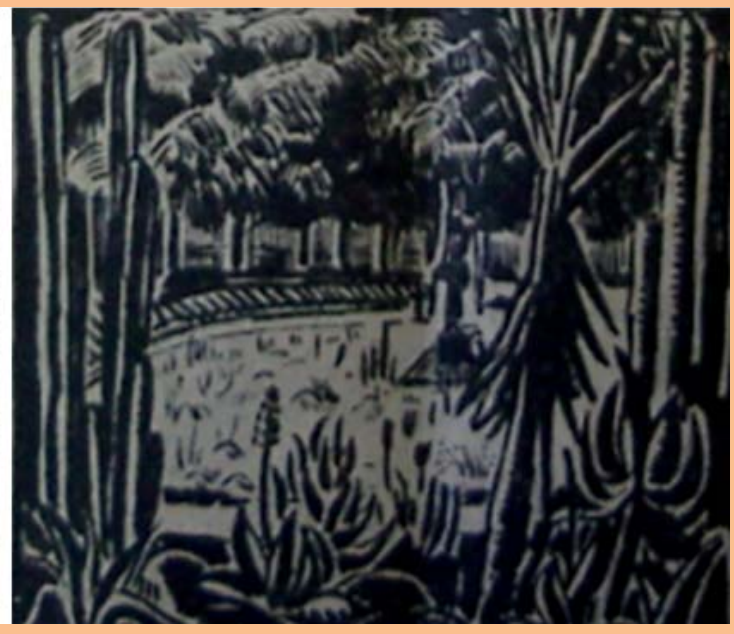

Fonte: Diario da Tarde 14/03/1935b.

nos trabalhos de Mina Warchavchik (DOURADO, 2009).

A Praça Euclides da Cunha foi, e ainda é, um dos projetos mais polêmicos que Burle Marx projetou. Muitos recifenses liderados pelo jornalista Mario Melo, na década de 1930, reagiram ao entender que um jardim com tais características seria uma tentativa de devolver a cidade para a selva.

A defesa que Burle Marx fez da utilização da vegetação da caatinga no Recife não se baseia apenas em suas qualidades paisagísticas intrínsecas, mas, sobretudo, na adequação por ser nativa da região e, conforme Jacques Leenhardt:

As plantas utilizadas provêm da região, mas elas jamais tiveram direito de cidadania na prática paisagística da época. A maneira de as apresentar é decisiva para a significação que elas terão no jardim. Burle Marx vai espalhar as cactáceas recolhidas por ele na caatinga, individualmente, no meio dos rochedos. Elas aparecerão como se cada uma delas levasse, na sua solidão e na sua forma, a memória do combate pela vida que teve no meio ambiente hostil onde cresceu (2008, p. 42; Grifo nosso).

Na Figura 7, temos uma vista parcial da praça no início de 1936 e, é interessante notar o porte do mandacaru (1) (Cereus jamacaru), que já possuía o cladódio lenhoso, o que nos leva a afirmar que os

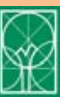

Soc. Bras. de Arborização Urbana mesmos foram plantados na praça em sua fase adulta, assim como ocorreu com algumas espécies arbóreas na Praça de Casa Forte.

Joelmir Marques da Silva 
Figura 7. Vista parcial do cactário da Praça Euclides da Cunha, em detalhe exemplares de Cactaceae e Bromeliaceae.

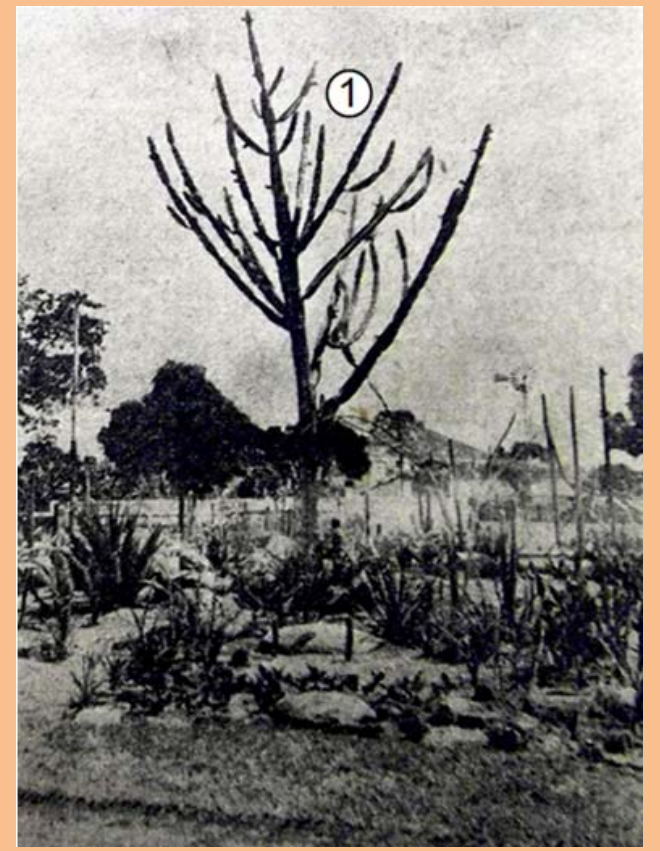

Fonte: Diario da Manhã, 16/02/1936.

Com a criação de um jardim em área litorânea, onde a condição edafoclimática é totalmente distinta da região a que pertence a vegetação da caatinga, principalmente as cactáceas, consegue Burle Marx não apenas introduzir a vegetação, mas também estabelecer uma correspondência entre as condições do nicho que ela ocupa e suas exigências ecofisiológicas. Isto só foi possível porque o paisagista buscou entender a planta em seu habitat, compreender suas associações, sua importância fitossociológica, enfim, sua inserção no espaço cênico natural (aspectos edafoclimáticos) que para o jardim é fundamental, até mesmo porque, para Burle Marx fazer jardim é também criar microclimas.

Em suas descrições sobre a Praça Euclides da Cunha e até mesmo nos relatos sobre a caatinga, o paisagista consegue tão bem descrever essa região. O que mais chama atenção é que, ao analisar a forma com que agrupa as espécies da praça, levando em consideração as especificidades de cada uma, lembra-nos a divisão claramente usada pelo povo sertanejo, ou seja, a caatinga concebida em duas faixas de vegetação, dois tipos distintos de paisagem.

A classificação está baseada no grau de umidade, o agreste, possuidor de maior umidade por estar mais próximo ao mar e solo mais profundo, com vegetação mais alta e densa; e sertão, mais seco, com solo raso e/ou pedregoso e vegetação mais baixa e pobre. Sertão é a caatinga no sentido habitual da palavra; é a caatinga propriamente dita, seca e agressiva.

Não é de admirar que a concepção desse jardim essencialmente brasileiro que é a Praça Euclides da Cunha, não se prenda só no caráter da vegetação, mas também em saber valorizar uma cultura e um saber popular, ou seja, o olhar para o autóctone. No projeto, Burle Marx dispõe a vegetação arbórea com a função de proteger o canteiro central, 
representado em sua maioria por cactáceas, dos ventos advindos do litoral, visto que, tal vegetação não suporta alta umidade.

No sentido periferia-centro, do jardim, foram dispostas espécies arbóreas no primeiro anel caracterizadas por espécies hipoxerófilas que são adaptadas a umidade; logo depois, outro anel composto por espécies arbóreas e arbustivas, vegetação de transição, que tem a função de absorver a umidade que conseguiu ultrapassar a vegetação do primeiro anel, permitindo assim que as espécies do cactário estivessem livres da

\section{Arqueologia Botânica da Praça Euclides da Cunha}

A arqueologia configura-se como a disciplina das ciências sociais que estuda os vestígios materiais culturais. Data do final do século 20 a consolidação do ramo da arqueologia, denominada de arqueologia histórica, que se detém na investigação dos vestígios do período histórico.

O conceito de arqueologia histórica apresenta poucas variações, sendo usualmente percebido como um campo de pesquisa de caráter multidisciplinar que abrange um amplo leque de fontes de informação de arquivos, dados oficiais, diários, cartas, mapas, plantas, fotografas, entrevistas, história oral e de métodos arqueológicos tradicionais. Assim, configura-se como o estudo do passado recente por meio dos vestígios materiais, nos quais contribuem para a descoberta da vida cotidiana e para a busca da compreensão do desenvolvimento histórico (ANDRADE, 2010).

Nesta perspectiva, o conhecimento da arqueologia botânica, ou botânica histórica, constitui a base para um correto entendimento de um jardim. No mais afortunado dos casos, a investigação documental umidade, além de receber incidência solar direta, uma vez que, são caracterizadas como heliófilas (PAULA et al., 2011). Com a disposição, de duas fileiras de árvores, Burle Marx valoriza conforme Dourado (2000) e Mafra (2007) o centro do jardim pela iluminação zenital e cria um espaço centrípeto. Com a criação da Praça Euclides da Cunha, Burle Marx concretiza seu objetivo ora expostos no Diario da Tarde de 14 /03/1935, que era dar a Pernambuco, em matéria de jardim, algo sólido e definitivo para se apresentar a prosperidade, dentro de uma expressão artística, cultural e de bom senso.

pode definir a lista de plantas usadas em um determinado sítio. É importante conhecer as espécies botânicas cultivadas nos diferentes períodos históricos mesmo que não seja possível um estudo mais aprofundado do aspecto históricobotânico do jardim (ONOFRE, 2002; DE ANGELIS e DE ANGELIS NETO, 2004).

O arquiteto Saúl Alcántara Onofre, estudioso dos jardins históricos do México, ressalta a importância do estudo detalhado da vegetação por permitir considerações diversas sobre o passado, sobre o presente e, definitivamente, sobre o futuro do jardim e salienta que a vegetação deve ser analisada segundo um método histórico e destaca "Por otra parte, es igualmente importante definir como la vegetación eran dispuestas en el pasado y como se alternaron en el transcurrir del tiempo" (ONOFRE, 2002, p.28).

Em casos complexos só a competência de um botânico ou um biólogo especializado poderá resolver o problema da identificação. O inventário florístico é o instrumento mais útil para aprofundar o conhecimento botânico de um determinado 
jardim, é a ferramenta indispensável para o início de um projeto de recuperação e para estabelecer um programa correto de manutenção e conservação (ONOFRE, 2002).

Em pesquisa sobre a conservação de jardins históricos o engenheiro agrônomo Bruno Luiz Domingos De Angelis e o engenheiro civil Generoso De Angelis Neto enfatizam a importância da técnica da fotointerpretação como instrumento imprescindível para se conhecer as transformações, principalmente do componente vegetal, ocorridas no jardim ao longo dos anos. Esse procedimento permite ao profissional, no momento em que, existirem dificuldades para o resgate e implantação da vegetação original, tomar decisões ex novo (DE ANGELIS e DE ANGELIS NETO, 2004).

Tendo ciência que a fitofisionomia do jardim é resultante de um contínuo equilíbrio entre o ciclo de vida do vegetal e o movimento cíclico das estações, o desenvolvimento e o depauperamento do componente florístico é condição natural. De acordo com Burle Marx, a planta:

É um ser vivo que obedece a um determinismo condicionado pelas leis do crescimento, da fisiologia, da biofísica e da bioquímica. Por outro lado, qualquer planta é o resultado de um longo processo histórico, no qual ela incorpora, em seu estado atual todas as experiências de uma longa linha de ascendentes, que se vai perder na indefinição dos primeiros seres. A planta por sua vez, goza no mais alto grau, da propriedade de ser instável. Ela é viva enquanto se altera. Ela sofre uma mutação constante, um desequilíbrio permanente, cuja finalidade é a própria busca de equilíbrio (1967, p. 37).

As intervenções realizadas no jardim devem ser duplamente criteriosas. Uma vez implantado, no que diz respeito ao controle da germinação e crescimento das plantas, a influência da intervenção humana é mínima nas causas de origem intrínseca, resumindo-se a serviços de manutenção. Embora o envelhecimento de um jardim seja desejável, isto não exime de responsabilidade a omissão humana.

Por assim ser, estudar e pretender a conservação de um jardim pressupõe, antes de tudo, conhecer a dinamicidade própria que envolve as transformações da vegetação ao longo do tempo. Conservar corretamente um jardim histórico significa, também, manter e valorizar as mensagens compositivas e históricas que o tornam um documento cultural, e não simplesmente uma coleção de plantas.

A arquiteta Maria José de A. Marcondes considera que as operações em jardins "só devem ser empreendidas após estudos aprofundados, que contemplem desde as escavações até coleta de todos os documentos referente ao respectivo jardim, suscetíveis de assegurar o caráter científico em um projeto” (MARCONDES, 2009, p.280).

A compreensão da evolução do componente vegetal do jardim possibilitará a escolha correta de espécies garantindo à autenticidade do bem, que conforme a Carta de Florença “a autenticidade de um jardim histórico diz respeito tanto ao desenho e proporção de suas partes como de sua composição, ou da escolha das espécies vegetais e outros materiais" (1981, Art. $9^{\circ}$ ). Na referida carta, mas precisamente em seu Art. 12, algumas considerações são feitas com relação ao plantio da vegetação, para garantir a autenticidade, onde exige que: " $a$ escolha das espécies de árvores, arbustos, plantas e flores que devem ser replantadas periodicamente deve ser conduzidas considerando-se os usos estabelecidos e aceitos em cada zona botânica e hortícula, com o objetivo de identificar as espécies originais e, assim, preservá-las”. 
Tais ações concorrem para a conservação do jardim em seu estado habitual que requer tanto reposições concretas, que sejam necessárias, como um programa de longo prazo de renovações periódicas, erradicação completa seguida de replantio com exemplares já formados (CARTA DE FLORENÇA, 1981, Art. $11^{\circ}$ ).

Diante do exposto acima, apresenta-se, s seguir, a arqueologia botânica da Praça Euclides da Cunha, tal procedimento só foi possível diante inúmeras

\section{O verde histórico da Praça Euclides da Cunha}

Da formação original da Praça Euclides da Cunha restam alguns registros fotográficos e relatos de Burle Marx em jornais e em discursos bem como depoimentos de Joaquim Cardozo. A planta baixa da praça não foi encontrada nos arquivos da Prefeitura da Cidade do Recife nem no escritório de Burle Marx \& Cia, no Rio de Janeiro, e consequentemente a lista da vegetação do projeto paisagístico também não.

No entanto, associando os achados florísticos mediante a fotointerpretação (Figuras 8 a 11) com iconografias que sejam: desenhos a nanquim de Burle Marx e fotos de várias épocas. Outras fontes analisadas foram os escritos e discursos do e sobre o paisagista referente às praças supracitadas, bem como, o levantamento florístico atual. Mesmo algumas fotos não tendo suas datas identificadas, tornaram-se fundamentais para o entendimento da evolução dos jardins e propiciaram o conhecimento de sua substância vegetal.

as especificações feitas por Burle Marx no artigo 'Jardins e Parques do Recife: Roberto Burle Marx para o Diario da Tarde’ de 14/03/1935b foi possível chegar a um total de 13 espécies distribuídas em 10 gêneros e 6 famílias botânicas. Destas, 10 foram identificadas em nível específico, 2 em nível genérico e 1 a nível de família (Tabela 1), o que possibilitou o entendimento da distribuição espacial da vegetação feita por Burle Marx.

Figura 8. Desenho de Burle Marx da Praça de Euclides da Cunha, 1935. 


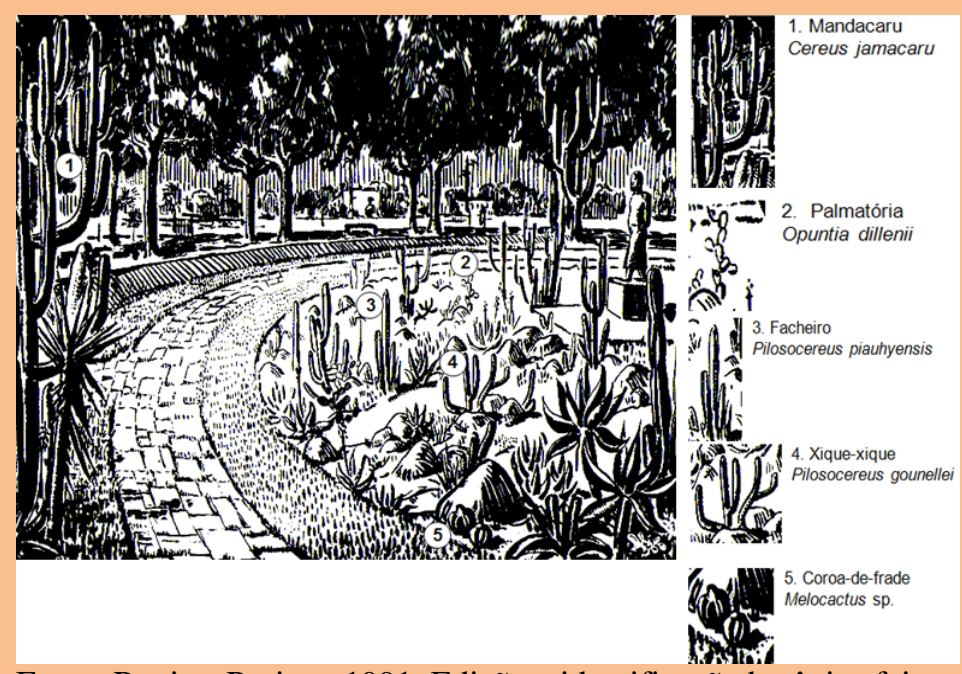

Fonte: Revista Projeto, 1991. Edição e identificação botânica feita pelo autor em 2012

Figura 9. Vista parcial do cactário da Praça Euclides da Cunha, 1936.

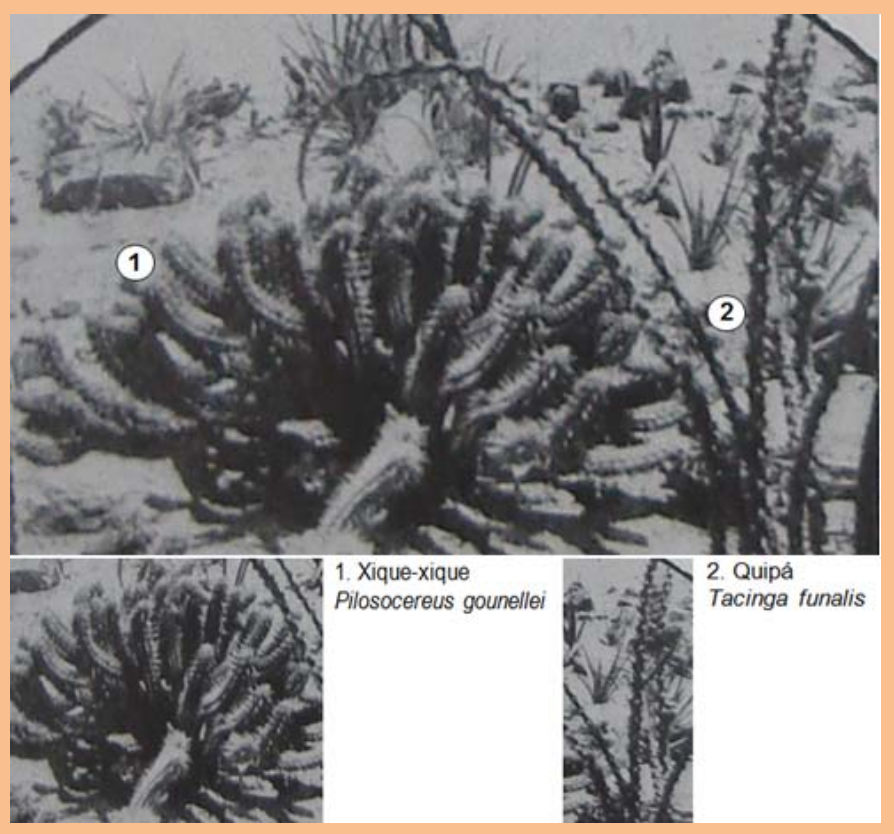

Fonte: Revista Cidade Maravilhosa, n.1, junho de 1936 in SILVA, 2010. Edição e identificação botânica feita pelo autor em 2012.

Figura 10. Vista parcial do cactário da Praça Euclides da Cunha, 1957. 

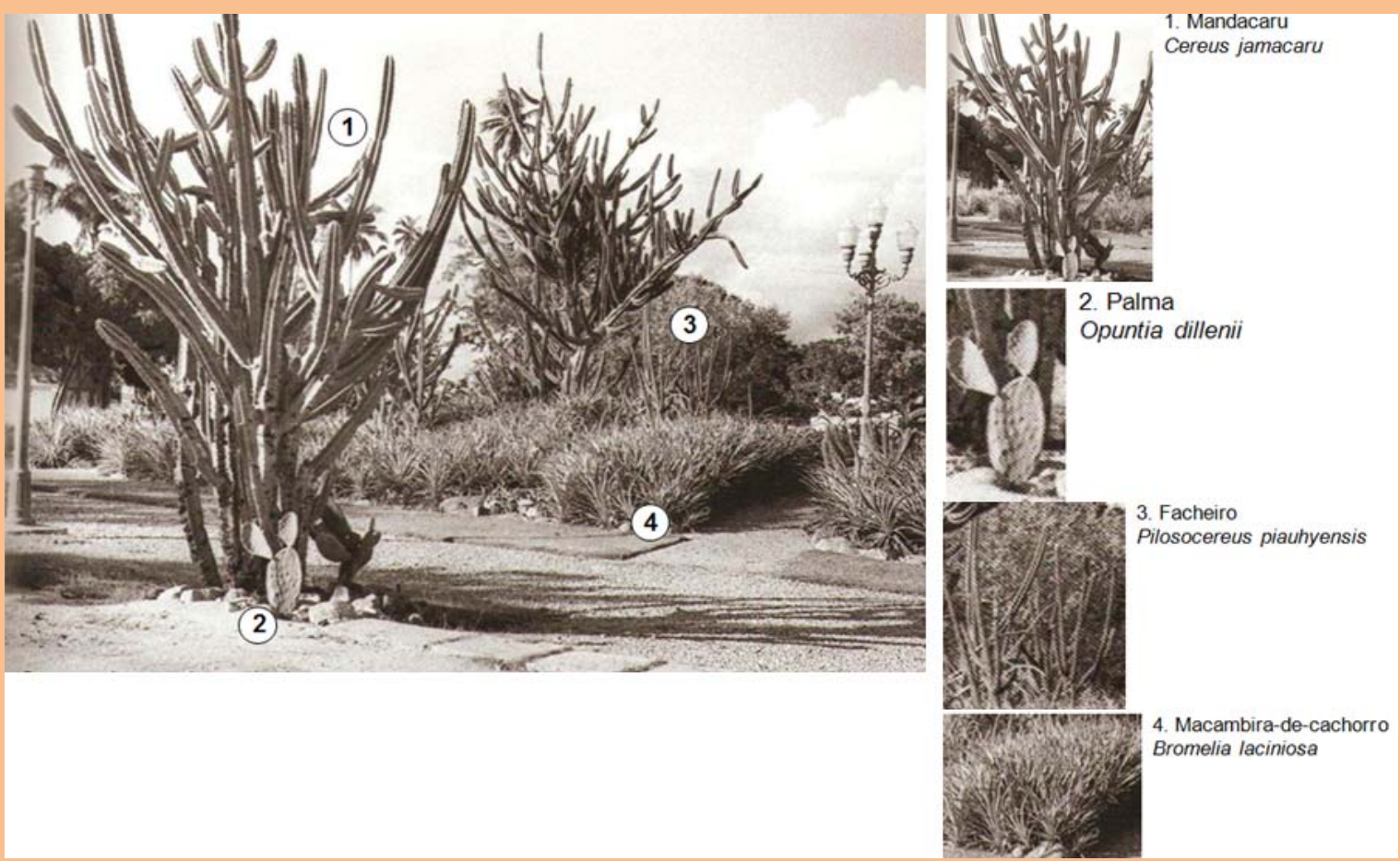

Fonte: Museu da Cidade do Recife in MAFRA, 2007. Edição e identificação botânica feita pelo autor em 2012

Figura 11. Vista parcial do cactário da Praça Euclides da Cunha, s/d.

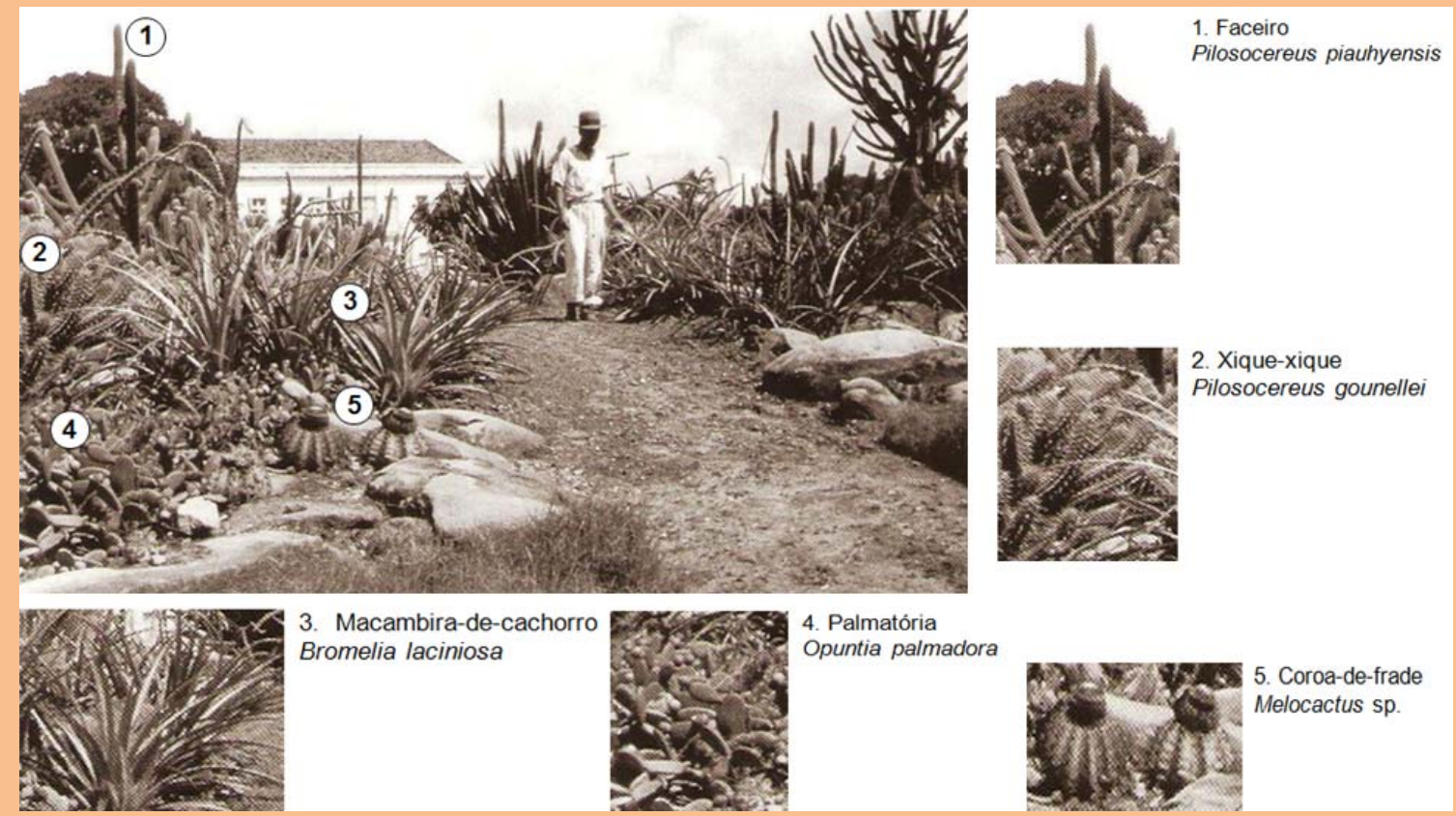

Fonte: Acervo de Gilda Pina in DOURADO, 2009. Edição e identificação botânica feita pelo autor em 2012. 
Tabela 1. Composição florística histórica da Praça Euclides da Cunha.

\begin{tabular}{l|l|l|l}
\hline \multicolumn{1}{c|}{ Nome Vernáculo } & \multicolumn{1}{c|}{ Nome Científico } & \multicolumn{1}{c}{ Família } & \multicolumn{1}{c}{$\begin{array}{c}\text { Domínio } \\
\text { Fitogeográfico }\end{array}$} \\
\hline Macambira-de-cachorro & Bromelia laciniosa & Bromeliaceae & Caatinga \\
\hline Mandacaru & Cereus jamacaru & Cactaceae & Caatinga; Cerrado \\
\hline Macambira-de-flecha & Encholirium spectabile & Bromeliaceae & $\begin{array}{l}\text { Caatinga; Cerrado; } \\
\text { Mata Atlântica }\end{array}$ \\
\hline Euforbiáceas & \multicolumn{1}{c}{-} & Euphorbiaceae & - \\
\hline Coroa-de-frade & Melocactus sp. & Cactaceae & - \\
\hline Palma & Opuntia palmadora & Cactaceae & Caatinga \\
\hline Xique-xique & Pilosocereus gounellei & Cactaceae & Caatinga; Cerrado \\
\hline Facheiro & Pilosocereus piauhyensis & Cactaceae & Caatinga \\
\hline Umbuzeiro & Spondias tuberosa & Anacardiaceae & $\begin{array}{l}\text { Caatinga; Cerrado; } \\
\text { Mata Atlântica }\end{array}$ \\
\hline Ipê & Tabebuia sp. & Bignoniaceae & - \\
\hline Quipá & Tacinga funalis & Cactaceae & Caatinga \\
\hline Joazeiro & Ziziphus joazeiro & Rhamnaceae & Caatinga \\
\hline Palma & Opuntia dillenii & Cactaceae & $\begin{array}{l}\text { Caatinga; } \\
\text { Mata Atlântica }\end{array}$ \\
\hline
\end{tabular}

\# Base de dados da Lista de Espécies da Flora do Brasil/ Jardim Botânico do Rio de Janeiro e do Centro Nordestino de Informações sobre Plantas.

Observa-se, na Tabela 1, que o quantitativo maior de espécies identificadas se refere, especificamente, ao canteiro central, fato este consequência da valorização, por parte do observador, das espécies presentes no cactário, obviamente, por serem mais “diferentes”. As únicas espécies arbóreas como o joazeiro (Z. joazeiro), o umbuzeiro (S. tuberosa) e o ipê (Tabebuia sp.) foram mencionadas por Burle Marx, em entrevista.

Com o descaso do poder público, a Praça Euclides da Cunha entrou em processo de descaracterização que atingiu principalmente o cactário, pelo crescimento de espécies arbóreas que além de não fazer parte do projeto original proporcionaram sombreamento permanente acarretando a extinção local das cactáceas, que resistiu até a década de 1980. Tais espécies foram disseminadas pelos mendigos que usavam o local como abrigo.

Face ao processo de descaracterização, uma parte da memória paisagística do Recife estava se perdendo. Frente a isso, a Prefeitura da Cidade do Recife junto ao Laboratório da Paisagem da Universidade Federal de Pernambuco iniciaram em 2001 as discussões sobre o processo de restauração do jardim. Na Tabela 2, observa-se a composição florística da Praça Euclides da Cunha no ano de 2002, antes da restauração, onde das 18 espécies presentes na praça, 8 são exóticas e/ou não pertencentes ao domínio fitogeográfico da caatinga, correspondendo a $44,44 \%$ do total. 
Tabela 2. Composição florística da Praça Euclides da Cunha antes da restauração

\begin{tabular}{|c|c|c|c|}
\hline Nome Vernáculo & Nome Científico & Família & $\begin{array}{c}\text { Domínio } \\
\text { Fitogeográfico }^{\#} \\
\end{array}$ \\
\hline Macaibeira & Acrocomia intumescens** & Arecaceae & Mata Atlântica \\
\hline Pereiro & Aspidosperma pyrifolium* & Apocynaceae & Caatinga; Cerrado \\
\hline Caramboleira & Averrhoa carambola* & Oxalidaceae & Exótica \\
\hline Jucá & Caesalpinia ferrea var. ferrea* & Caesalpiniaceae & Caatinga \\
\hline Catingueira & Caesalpinia pyramidalis** & Caesalpiniaceae & Caatinga \\
\hline Imbaúba & Cecropia laetiviren* & Cecropiaceae & Amazônia \\
\hline Paineira & Chorisia glaziovii* & Bombacaceae & $\begin{array}{l}\text { Caatinga; Cerrado; Mata } \\
\text { Atlântica }\end{array}$ \\
\hline Imburana & Commiphora leptophloeos* & Burseraceae & Caatinga; Cerrado \\
\hline Tamboril & Enterolobium contortisiliquum * & Mimosaceae & $\begin{array}{l}\text { Caatinga; Cerrado; } \\
\text { Mata Atlântica }\end{array}$ \\
\hline Palmeira-Filipina & Livistona rotundifolia** & Arecaceae & Exótica \\
\hline Mangueira & Mangifera indica*** & Anacardiaceae & Exótica \\
\hline Jurema-branca & Mimosa artemisiana* & Mimosaceae & Caatinga; Mata Atlântica \\
\hline Aroeira & Myracrodruon urundeuva* & Anacardiaceae & $\begin{array}{l}\text { Caatinga; Cerrado; Mata } \\
\text { Atlântica }\end{array}$ \\
\hline Acácia-mimosa & Pithecellobium dulce** & Mimosaceae & $\begin{array}{l}\text { Caatinga; Amazônia; Mata } \\
\text { Atlântica }\end{array}$ \\
\hline Goiabeira & Psidium guajava** & Myrtaceae & $\begin{array}{l}\text { Caatinga; Amazônia; Mata } \\
\text { Atlântica; Cerrado }\end{array}$ \\
\hline Palmeira-imperial & Roystonea oleracea* & Arecaceae & Exótica \\
\hline Azeitoneira & Syzygium jambolanum** & Myrtaceae & Exótica \\
\hline Ipê-roxo & Tabebuia impetiginosa*** & Bignoniaceae & $\begin{array}{l}\text { Caatinga; Amazônia; } \\
\text { Cerrado; Pantanal; Mata } \\
\text { Atlântica }\end{array}$ \\
\hline Juazeiro & Ziziphus joazeiro*** & Rhamnaceae & Caatinga \\
\hline
\end{tabular}

*Espécie presente fora do cactário; **Espécie presente dentro do cactário; ***Espécie presente dentro e fora do cactário. Fonte: Laboratório da Paisagem/UFPE - Inventário dos Jardins de Burle Marx no Recife, 2011.

O projeto de restauração da Praça Euclides da Cunha fundamentou-se na Carta de Florença (1981), em pesquisas detalhadas da historiografia da praça, entrevistas com pessoas envolvidas com o assunto, bem como da vegetação da caatinga.

A restauração teve inicio em julho de 2003 e foi concluída em maio de 2004. A vegetação da caatinga introduzida na execução do projeto de restauração foi proveniente da sementeira da
Companhia Hidrelétrica do São Francisco, localizada no sertão do Estado de Alagoas. O estudo da vegetação foi o aspecto principal no qual se debruçou a arquiteta Liana Mesquita, em estudo minucioso das espécies da caatinga. Na Tabela 3 pode-se ver a composição florística da Praça Euclides da Cunha ao final da restauração, representada por 28 espécies, 24 gêneros e 15 famílias botânicas. Destas espécies 4 são exóticas. 
Tabela 3. Composição florística da Praça Euclides ao final da restauração

\begin{tabular}{|c|c|c|c|}
\hline Nome Vernáculo & Nome Científico & Família & $\begin{array}{c}\text { Domínio } \\
\text { Fitogeográfico }^{\#} \\
\end{array}$ \\
\hline Macaibeira & Acrocomia intumescens & Arecaceae & Mata Atlântica \\
\hline Pereiro & Aspidosperma pyrifolium & Apocynaceae & Caatinga; Cerrado \\
\hline Caramboleira & Averrhoa carambola & Oxalidaceae & Exótica \\
\hline Mororó & Bauhinia forficata & Caesalpiniaceae & $\begin{array}{l}\text { Caatinga; } \\
\text { Mata Atlântica } \\
\end{array}$ \\
\hline Macambira-de-cachorro & Bromelia laciniosa & Bromeliaceae & Caatinga \\
\hline Jucá & Caesalpinia ferrea var. ferrea & Caesalpiniaceae & Caatinga \\
\hline Catingueira & Caesalpinia pyramidalis & Caesalpiniaceae & Caatinga \\
\hline Mandacaru & Cereus jamacaru & Cactaceae & Caatinga; Cerrado \\
\hline Jurema & Chloroleucon tortum & Mimosaceae & Mata Atlântica \\
\hline Paineira & Chorisia glaziovii & Bombacaceae & $\begin{array}{l}\text { Caatinga; Cerrado; Mata } \\
\text { Atlântica }\end{array}$ \\
\hline Macambira-de-fleche & Encholirium spectabile & Bromeliaceae & $\begin{array}{l}\text { Caatinga; Cerrado; Mata } \\
\text { Atlântica }\end{array}$ \\
\hline Tamboril & Enterolobium contortisiliquum & Mimosaceae & $\begin{array}{l}\text { Caatinga; Mata Atlântica; } \\
\text { Cerrado }\end{array}$ \\
\hline Mulungu & Erythrina velutina & Fabaceae & $\begin{array}{l}\text { Caatinga; Amazônia, } \\
\text { Cerrado; Mata Atlântica }\end{array}$ \\
\hline Palmeira-filipina & Livistona rotundifolia & Arecaceae & Exótica \\
\hline Mangueira & Mangifera indica & Anacardiaceae & Exótica \\
\hline Bom-nome & Maytenus rigida & Celastraceae & Caatinga; Cerrado \\
\hline Coroa-de-frade & Melocactus bahiensis & Cactaceae & Caatinga; Cerrado \\
\hline Jurema-branca & Mimosa artemisiana & Mimosaceae & Caatinga; Mata Atlântica \\
\hline Aroeira & Myracrodruon urundeuva & Anacardiaceae & $\begin{array}{l}\text { Caatinga; Cerrado; Mata } \\
\text { Atlântica }\end{array}$ \\
\hline Palma & Opuntia palmadora & Cactaceae & Caatinga \\
\hline Xique-xique & Pilosocereus gounellei & Cactaceae & Caatinga; Cerrado \\
\hline Facheiro & Pilosocereus piauhyensis & Cactaceae & Caatinga \\
\hline Palmeira-imperial & Roystonea oleracea & Arecaceae & Exótica \\
\hline Umbuzeiro & Spondias tuberosa & Anacardiaceae & $\begin{array}{l}\text { Caatinga, Cerrado, Mata } \\
\text { Atlântica }\end{array}$ \\
\hline Craibeira & Tabebuia aurea & Bignoniaceae & $\begin{array}{l}\text { Caatinga; Amazônia; } \\
\text { Cerrado; Mata Atlântica; } \\
\text { Pantanal }\end{array}$ \\
\hline Ipê-rosa & Tabebuia impetiginosa & Bignoniaceae & $\begin{array}{l}\text { Amazônia; Caatinga, } \\
\text { Cerrado, Mata Atlântica; } \\
\text { Pantanal }\end{array}$ \\
\hline Quipá & Tacinga funalis & Cactaceae & Caatinga \\
\hline Joazeiro & Zizyphus joazeiro & Rhamnaceae & Caatinga \\
\hline
\end{tabular}

\# Base de dados da Lista de Espécies da Flora do Brasil/ Jardim Botânico do Rio de Janeiro e do Centro Nordestino de Informações sobre Plantas.

Com o passar do tempo, e por falta de manutenção contínua, algumas espécies não conseguiram se estabelecer, por ser uma praça diferenciada já que a vegetação predominante - espécies da caatinga-, não condiz com as condições edafoclimáticas da região. Na Tabela 4 apresenta-se a composição florística da Praça Euclides da Cunha no ano de 2013, representada por 24 espécies, 20 gêneros e 13 famílias botânicas. 
Tabela 4. Composição florística da Praça Euclides da Cunha em 2013.

\begin{tabular}{l|l|l}
\hline \multicolumn{1}{c|}{ Nome Vernáculo } & \multicolumn{1}{c}{ Nome Científico } & \multicolumn{1}{c}{ Família } \\
\hline Macaibeira & Acrocomia intumescens & Arecaceae \\
\hline Pereiro & Aspidosperma pyrifolium & Apocynaceae \\
\hline Caramboleira & Averrhoa carambola & Oxalidaceae \\
\hline Macambira-de-cachorro & Bromelia laciniosa & Bromeliaceae \\
\hline Jucá & Caesalpinia ferrea var. ferrea & Caesalpiniaceae \\
\hline Catingueira & Caesalpinia pyramidalis & Caesalpiniaceae \\
\hline Mandacaru & Cereus jamacaru & Cactaceae \\
\hline Jurema & Chloroleucon tortum & Mimosaceae \\
\hline Paineira & Chorisia glaziovii & Bombacaceae \\
\hline Macambira-de-fleche & Encholirium spectabile & Bromeliaceae \\
\hline Tamboril & Enterolobium contortisiliquum & Mimosaceae \\
\hline Mulungu & Erythrina velutina & Fabaceae \\
\hline Candelabro & Euphorbia lactea & Euphorbiaceae \\
\hline Palmeira-filipina & Livistona rotundifolia & Arecaceae \\
\hline Mangueira & Mangifera indica & Anacardiaceae \\
\hline Jurema-branca & Mimosa artemisiana & Mimosaceae \\
\hline Palma & Opuntia palmadora & Cactaceae \\
\hline Xique-xique & Pilosocereus gounellei & Cactaceae \\
\hline Facheiro & Pilosocereus piauhyensis & Cactaceae \\
\hline Palmeira-imperial & Roystonea oleracea & Arecaceae \\
\hline Umbuzeiro & Spondias tuberosa & Anacardiaceae \\
\hline Craibeira & Tabebuia aurea & Bignoniaceae \\
\hline Ipê-rosa & Tabebuia impetiginosa & Bignoniaceae \\
\hline Joazeiro & Zizyphus joazeiro & Rhamnaceae \\
\hline & &
\end{tabular}

Confrontando a composição florística da Praça Euclides da Cunha, conforme as especificações de Burle Marx e da identificação da vegetação a partir da fotointerpretação (Tabela 1) com o inventário florístico de 2013 pôde-se constatar que espécies da Família Euphorbiaceae bem como, a coroa-de-frade (M. bahiensis) e o quipá (T. funalis) não estão presentes na praça, no entanto, com exceção das espécies de Euphorbiaceae, a coroa-de-frade e o quipá foram introduzidos no momento da restauração, mas que por problemas de manutenção, principalmente correlata a drenagem da água do cactário, não resistiram. A única espécie de Euphorbiaceae presente na praça hoje é o candelabro (E. lactea) proveniente da Índia.

Espécies como o ipê-rosa (T. impetiginosa), o pereiro (A. pyrifolium), a paineira (C. glaziovii), o jucá (C. ferrea var. ferrea), a jurema-branca (M. artemisiana) e o tamboril (E. contortisiliquum) já se encontravam na praça, antes da restauração, e possuíam porte adulto. Outras como a catingueira (C. pyramidalis), a jurema (C. tortum), o mulungu (E. velutina) e a craibeira (T. aurea) foram introduzidas, no momento da restauração e mesmo não tendo sido especificados por Burle Marx, são espécies típicas da região da caatinga e que fazem parte da paisagem sertaneja.

Hoje, ao contemplar a Praça Euclides da Cunha em sua totalidade percebe-se claramente a mensagem que Burle Marx deixou, em 1935, para Pernambuco, que foi doar um jardim em que se achem aliadas a higiene e a arte, ao par da educação e cultura. 
A partir das questões abordadas ao longo deste artigo, pode-se entender que, enquanto a conscientização para a conservação e o respeito aos jardins for apenas uma abordagem conceitual e não uma prática cotidiana ainda teremos que vivenciar a descaracterização de obras importantes. Conforme Mário Quintana, “O que mata um jardim não é mesmo alguma ausência nem o abandono (...) o que mata um jardim é esse olhar vazio de quem por eles passa indiferente” (2007, p. 15). Contudo, este estudo mostra que há uma necessidade emergente de viabilizar uma relação mais estreita com o campo da conservação, mas precisamente do componente vegetal diante da sua efemeridade. A intenção é firmar a ideia de uma cultura paisagística que venha aperfeiçoar um esforço teórico e uma prática que rompam as resistências de um cotidiano urbano, sem memória e sem respeito aos jardins, entendidos aqui como um bem, que se constituem em elementos fundamentais para contarmos a história da paisagem onde vivemos.

\section{REFERÊNCIAS BIBLIOGRÁFICAS}

AB’SÁBER, A.; MARIGO, L. C. Ecossistemas do Brasil. São Paulo: Metalivros, 2006.

ANDRADE, I. El-Jaick. Ruínas do Antigo Engenho Novo no Núcleo Histórico Rodrigues Caldas da Colônia Juliano Moreira: pesquisa histórica e iconográfca. Revista de história da arte e arqueologia, São Pulo, v. s/n, n. 13, 2010.

BEST, J. W. Como investigar em educacíon. 2. ed. Madri: Morara S.a, 1972.

CALS, Soraia. Roberto Burle Marx: uma fotobiografia. Rio de Janeiro: S. Cals, 1995.

CARTA DE FLORENÇA (1981). In: CURY, I. (Brasil). Cartas Patrimoniais. 2. ed. Rio de Janeiro: IPHAN, 2000. p. 253-258. Edições do Patrimônio.

CUNHA, E. Os Sertões. São Paulo: Três, 1909.

DE ANGELIS, B. L. D. \& DE ANGELIS NETO, G. Jardins Históricos: introduzindo a questão. Paisagem e Ambiente: Ensaios, São Paulo, n. 19, p. 31-4, 2004.

DIARIO DA MANHÃ. O Jardim da Casa Forte. 22/05/1935.

DIARIO DA TARDE. Os jardins e a arborização da cidade. 14/03/1935a.

Jardins e Parques do Recife: Roberto Burle Marx para o Diario da Tarde. 14/03/1935b.

. Modernidade Verde: Jardins de Burle Marx. São Paulo: Edusp:senac, 2009.

LEENHARDT, J. A exigência social de paisagem: reflexões a partir de Burle Marx. In: TERRA, Carlos; ANDRADE, Rubens. Paisagens Culturais: Contrastes Sul-Americanos. Rio de Janeiro: EBA, 2008. p. 37-45.

MAFRA, F. Natureza organizada é obra de arte: Roberto Burle Marx em Recife. 107f. Dissertação (Mestrado em Desenvolvimento Urbano) - Departamento de arquitetura e urbanismo, Universidade Federal de Pernambuco, Recife, 2007. 
MARCONDES, M. J. A. Modernismo e preservação: jardins históricos e valor documental. In: SÁ CARNEIRO, A. R. \& BERTRUY, R. I. P. Jardins Históricos Brasileiros e Mexicanos. Recife: Universitária UFPE, 2009. p. 271-292.

MATOS, E. \& PAGANUCCI, L. Árvores para cidades. Salvador: Ministério Público do Estado da Bahia: Solisluna, 2009.

MARX, B. Minha experiência em Pernambuco (conferência). In: MIRANDA, M. C. T. Anais... Seminário de tropicologia: Homem, terra e trópico. Recife: FUNDAJ, Ed. Massangana,1992.

ONOFRE, S. A. Diseño, planificación y conservación de paisajes y jardines. Universidad Autónoma Metropolitana-Azcapotzalco: México, 2002.

PAULA, E. S.; SILVA, J. M.; MENEZES, P. C.; SÁ CARNEIRO, A. R. \& MELO, V. L. M. O. A paisagem da caatinga: um gesto de Burle Marx na Praça Euclides da Cunha. Revista Paisagem e Ambiente, São Paulo, n.29, p. 11-24, 2011.

QUINTANA, M. A cor do invisível. São Paulo: Globo, 1997.

SANDEVILLE JUNIOR, E. Paisagem completa: Breve viagem pela obra de Burle Marx. Projeto Design, São Paulo, n. 179, p.89-90, 1994.

SILVA, A. F. Jardins do Recife: uma história do paisagismo no Brasil (1872-1937). Recife: CEPE Editora, 2010. 244p.

TRIPODI, T.; FELLIN, P. e MEYER, H. J. Análises da pesquisa social: diretrizes para o uso de pesquisa em serviço social e em ciências sociais. Rio de Janeiro: Francisco Alves, 1975.

TRUJILLO, A. F. Metodologia da ciência. Rio de Janeiro: Kennedy, 1974. 